\title{
ORIGINAL \\ PROF-839 \\ EVALUATION OF PARAOXONASE (PON) GLUTAMATE OXALOACETATE TRANSAMINASE (SGOT)
}

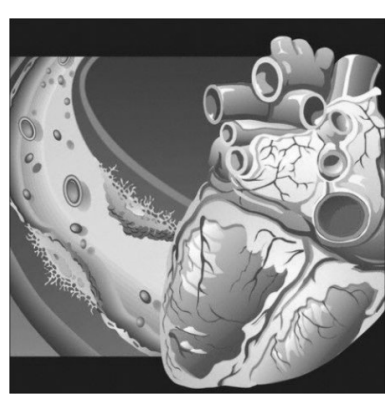

\author{
MISS ROBINA RASHID, M.Sc \\ Lecturer Independent Medical College \\ Faisalabad \\ DR. KHALIL-UR-REHMAN, PhD \\ Associate Professor Biochemistry \\ University of Agriculture, Faisalabad.
}

DR M ZAHOOR UL HASSAN DOGAR, PhD

Associate Professor Biochemistry (OPS)

Punjab Medical College Faisalabad.

\section{Dr. Muhammad Aslam, MBBS \\ DHQ Hospital Faisalabad}

*Miss. Sadia Falak, M.Sc

*Department of Chemistry, University of Agriculture, Faisalabad.

*Miss Huma Saleem, M.Sc

*Department of Chemistry, University of Agriculture,

Faisalabad.

Copyright: 10 September, 2004.

\begin{abstract}
Objectives: This study was undertaken for the comparative evaluation of paraoxonase (PON) and Serum Glutamate Oxaloacetate Transaminase (SGOT) levels in male cardiac patients and normal subjects and the evaluation of cardiac dysfunction by assaying the enzymes PON and SGOT. Study design: Prospective Period: Six months from June 2003 to Nov 2003. Setting: DHQ Hospital Faisalabad/ Department of Chemistry Agriculture University of Faisalabad. Method \& Materials: The blood of the male cardiac patients as well as control subjects was collected and serum was separated, that was used for the determination of PON and SGOT activity. Twenty blood samples from male cardiac patients from DHQ Faisalabad was collected. At the same time 20 other male subjects which were not suffering from any active cardiac disease were selected as control. Ante-cubital venous blood samples without anticoagulant were centrifuged to obtain the serum. Results: Paraoxonase is present in the blood on the HDL and it can break down the oxidized LDL to non-harmful products therefore the activity of HDL and LDL was determined along with other two parameters. It was observed that the cardiac male patients had low activity of PON and HDL as compared to normal. Whereas activity of SGOT and LDL was lower in normal subjects as compared to the cardiac male patients. The activity of PON and $\mathrm{HDL}(56.86 \pm 0.94 \mathrm{U} / \mathrm{ml}),(14.58 \pm 0.14 \mathrm{mg} / \mathrm{dl})$ is lower in cardiac male patients as compared to normal $(241 \pm 0.85 \mathrm{U} / \mathrm{ml}),(46.66 \pm 1.10 \mathrm{mg} / \mathrm{dl}) \mathrm{respectively}$, while SGOT $(219.0 \pm 2$ $\mathrm{U} / \mathrm{ml}$ and LDL $(177.3 \pm 4.73 \mathrm{mg} / \mathrm{dl})$ was greater as compared to the control $(24.78 \pm 2.32 \mathrm{U} / \mathrm{ml})$ and $(119.2 \pm 1.08 \mathrm{mg} / \mathrm{dl})$ respectively. Conclusion: It is concluded that there was an inverse correlation between serum PON and SGOT.
\end{abstract}




\section{INTRODUCTION}

Atherosclerosis is a condition where the walls of the arteries are damaged and narrowed by deposits of plaque (cholesterol and other fatty substances, calcium, fibrin and cellular wastes), eventually blocking off the flow of blood. When thrombus blocks the flow of blood through the entire artery, a heart attack or a stroke occurs. High blood levels of cholesterol-particularly the cholesterol carried by low-density lipoprotein (LDL), a protein found in blood)-are associated with an increased risk of atherosclerosis. Normal LDL in plasma is not oxidized. Oxidation of LDL is believed to contribute to the development of atherosclerosis ${ }^{1}$. Macrophage cells preferentially take up oxidized LDL, become loaded with lipids, and convert into "foam cells"2.

Coronary heart disease is associated with significantly decreased activity of paraoxonase (PON) as compared to the controls ${ }^{3}$ Some prospective studies have shown that serum total cholesterol concentration is positively associated with subsequent risk of coronary heart disease. Human paraoxonase (PON) is a high density lipoprotein (HDL) associated esterase that hydrolyses lipoperoxides. PON is a protective factor against oxidative modification of LDL and may therefore play an important role in the prevention of atherosclerotic process $^{4}$. Vitamin $E$, Vitamin $C$ and $\beta$-carotene (Fruits and Vegetables) are antioxidants and prevents the oxidation of LDL and atherogenesis ${ }^{5}$. Vitamin $C$ and $E$ are dietary antioxidants, scavenge free oxygen radical products that may decrease PON activity ${ }^{6}$. The level of PON activity is reduced in smokers than non smokers ${ }^{7}$. PON activity is significantly lower in diabetic as compared to nondiabetics ${ }^{8}$.

There are number of factors involved in the onset of cardiac diseases such as atherosclerosis, diabetes mellitus, Hypertension and smoking ${ }^{9,10,11,12}$. Para oxonase is located in the blood on the HDL and it can breakdown the oxidized LDL to non-harmful products. There is a strong inverse relationship between the activity of PON in the blood and risk of heart disease, lower activity of para-oxonase in the blood is associated with higher risk of heart disease $^{13}$.

Increased LDL oxidation is associated with coronary artery diseases. HDL levels are inversely related to risk of coronary artery disease. HDL prevents atherosclerosis by reverting the stimulatory effect of oxidized LDL on monocyte infiltration. The HDL associated, enzyme paraoxonase (PON) inhibits the oxidation of $\mathrm{LDL}^{14}$.

\section{MATERIAL \& METHODS}

Twenty blood samples from male cardiac patients from DHQ Faisalabad was collected, after the confirmation by cardiologist. At the same time 20 other male subjects which were not suffering from any active cardiac disease, selected as control for comparison. Ante-cubital venous blood samples without anticoagulant were centrifuged to obtain the serum.

The serum obtained was used for paraoxonase (PON) and SGOT assay, HDL cholesterol and LDL cholesterol. Medical record and questionnaires were used to obtain data above dietary habits, history of hypertension, diabetes mellitus, cardiovascular disease and smoking etc.

\section{Paraoxonase (PON) Assay}

Paraoxonase activity towards phenyl acetate was measured spectrophotometrically at $270 \mathrm{~nm}$ wavelength ${ }^{15}$. The assay mixture included $1 \mathrm{mM}$ phenyl acetate and $1 \mathrm{mM} \mathrm{CaCl}$ in $0.05 \mathrm{M}_{2}$ glycine buffer, ( $\mathrm{pH}$ 10.3), non-enzymatic hydrolysis of phenyl acetate was subtracted from the total rate of hydrolysis. The $270 \mathrm{E}$ for the reaction was $1310 \mathrm{M}^{-1}$ $\mathrm{cm}^{-115}$

$$
\text { Activity }=\frac{\text { Sop } x \text { ablution factor } x 10^{9}}{1310 \times 10^{3}}
$$

\section{SGOT Assay}

SGOT activity in serum samples was measured by Human diagnostic Kit method. (cat no. 12011).

HDL and LDL Cholesterol measurements HDL \& LDL cholesterol levels in serum samples 
were measured by enzymatic spectrophotometric method, using commercially available Kits of $E$. Merck company. LDL cholesterol was calculated according to the Friedewald formula.

\section{Statistical Analysis}

The results were expressed as mean \pm SD. LSD used for statistical level of significance at $\mathrm{P}<0.05(5 \%)^{16}$.

\section{RESULTS \& DISCUSSION}

Mean values of PON were recorded in both cardiac patients and control (Table-I) among the mentioned categories Minimum mean value of PON was recorded in hypertensive and diabetic cardiac patients $56.86 \pm 0.94$ and in controls $126.8 \pm 2.51$ which is significantly greater than the patients, but less among the categories. Mean value of PON was $241 \pm 0.85 \mathrm{U} / \mathrm{mL}$ in controls is significantly greater as compared to the patient of all categories.

These results were in harmony with that of James et $\mathrm{al}^{7}$ who reported that smoking is associated with reduced serum paraoxonase activity in patients with coronary artery disease. These results are extensively supported by Boemi et al ${ }^{8}$ who reported that enzyme activity of PON was significantly lower in diabetics as compared to the control. The fruits and vegetable containing Vitamin $E, C$ and $\beta$ carotene decrease the LDL cholesterol oxidation and increase PON activity 5 .

\begin{tabular}{|l|c|c|}
\hline \multicolumn{2}{|c|}{ Table-I. Mean values of PON in male cardiac patients and control subjects } \\
\hline Categories & Mean in normal subjects U/mL & Mean in cardiac patients U/mL \\
\hline Non smokers & $241 \pm 0.85$ & $91.89 \pm 2.26$ \\
\hline Smokers & $222.1 \pm 3.38$ & $77.57 \pm 0.77$ \\
\hline Hypertensive & $197.1 \pm 4.14$ & $73 \pm 1.66$ \\
\hline Diabetics & $168.1 \pm 6.55$ & $70.21 \pm 1.09$ \\
\hline Hypertensive \& smokers & $148.4 \pm 2.0$ & $64.99 \pm 0.53$ \\
\hline Diabetics \& smokers & $137.3 \pm 2.08$ & $61.33 \pm 0.75$ \\
\hline Hypertensive \& diabetics & $126.8 \pm 2.51$ & $56.86 \pm 0.94$ \\
\hline
\end{tabular}

\begin{tabular}{|l|c|c|}
\hline \multicolumn{2}{|c|}{ Table-III. Mean value of HDL cholesterol in male cardiac patients and control subjects } \\
\hline Categories & Mean in normal subjects mg/dl & Mean in cardiac patients mg/dl \\
\hline Non smokers & $46.66 \pm 1.10$ & $32.73 \pm 0.15$ \\
\hline Smokers & $32.09 \pm 1.88$ & $29,70 \pm 0.37$ \\
\hline Hypertensive & $30.20 \pm 1.38$ & $29.30 \pm 0.56$ \\
\hline Diabetics & $28 \pm 1.26$ & $23.74 \pm 0.66$ \\
\hline Hypertensive \& smokers & $26.60 \pm 0.51$ & $21.60 \pm 0.56$ \\
\hline Diabetics \& smokers & $24.60 \pm 0.74$ & $18.34 \pm 0.036$ \\
\hline Hypertensive \& diabetes & $23.37 \pm 0.94$ & $14.58 \pm 0.14$ \\
\hline
\end{tabular}




\begin{tabular}{|l|c|c|}
\hline \multicolumn{2}{|c|}{ Table-II. Mean values of SGOT in male cardiac patients and controls } \\
\hline Categories & Mean in normal subjects U/mL & Mean in cardiac patients UIm L \\
\hline Non smokers & $24.78 \pm 2.32$ & $95.33 \pm 1.53$ \\
\hline Smokers & $50.78 \pm 0.57$ & $149.7 \pm 4.51$ \\
\hline Hypertensive & $55.77 \pm 2.81$ & $163.7 \pm 2.06$ \\
\hline Diabetics & $73.12 \pm 1.18$ & $180 \pm 2.65$ \\
\hline Hypertensive \& smokers & $78.80 \pm 0.91$ & $189.7 \pm 1.53$ \\
\hline Diabetics \& smokers & $82.46 \pm 2.15$ & $209 \pm 2$ \\
\hline Hypertensive \& diabetics & $135.2 \pm 4.40$ & $219 \pm 2$ \\
\hline
\end{tabular}

\begin{tabular}{|l|c|c|}
\hline \multicolumn{2}{|c|}{ Table-IV. Mean values of LDL cholesterol in male cardiac patients and controls } \\
\hline Categories & Mean in normal subjects mg/dl & Mean in cardiac patients mg/dl \\
\hline Non smokers & $119.2 \pm 1.08$ & $140.7 \pm 2.52$ \\
\hline Smokers & $135.7 \pm 1.41$ & $150.3 \pm 1.53$ \\
\hline Hypertensive & $139.4 \pm 0.89$ & $156.3 \pm 3.06$ \\
\hline Diabetics & $156.3 \pm 3.06$ & $145.4 \pm 1.35$ \\
\hline Hypertensive \& smokers & $157.3 \pm 4.73$ & $150.1 \pm 0.83$ \\
\hline Diabetics \& smokers & $155.8 \pm 1.11$ & $173 \pm 4.358$ \\
\hline Hypertensive \& diabetes & $161.1 \pm 1.38$ & $177.3 \pm 4.73$ \\
\hline
\end{tabular}

Maximum mean value of SGOT recorded in both cardiac hypertensive and diabetic patients was $219 \pm 2 \mathrm{U} / \mathrm{mL}$ and in control $135.2 \pm 4.40 \mathrm{U} / \mathrm{mL}$ which was less as compared to the patients as well as among all categories. Minimum mean value of SGOT recorded in cardiac non-smokers patient was $95.33 \pm 1.53 \mathrm{U} / \mathrm{mL}$ and in control $24.78 \pm 2.32$ was significantly lower as compared to the patients as well as among all categories.

Mean values of $\mathrm{HDL}$ cholesterol were recorded both in non-smokers cardiac patients $32.73 \pm 1.15 \mathrm{mg} / \mathrm{dl}$ and in controls. $46.66 \pm 1.10$ which was high among all categories.

The HDL cholesterol control value was significantly higher in control as compared to the cardiac patients. Minimum mean value was recorded in both hypertensive and diabetics as $14.58 \pm 0.14 \mathrm{mg} / \mathrm{dl}$ and in controls $23.37 \pm 0.94$ among the all categories. But control value was significantly higher as compared to the patients. HDL-C level was increased in nonsmokers which result in the low risk of CHD. HDL cholesterol levels are inversely related to the risk of coronary artery disease. HDL cholesterol prevents atherosclerosis by reverting the stimulatory effect of oxidized LDL on monocyte infiltration and by HDL-C associated enzyme PON ${ }^{14}$.

Maximum mean value of LDL was observed in cardiac hypertensive and diabetic patients $(177.3 \pm 4.73 \mathrm{mg} / \mathrm{dL})$. The controls value $161.1 \pm 1.35$ $\mathrm{mg} / \mathrm{dL}$ was significantly lower as compared to the patient, among all categories. Minimum mean value 
of LDL cholesterol was recorded in non-smokers. Patients $(140.7 \pm 2.52 \mathrm{mg} / \mathrm{dL})$ and in controls $(119.2 \pm 1.08 \mathrm{mg} / \mathrm{dL})$ which was significantly lower as compared to patient as well as among all categories. LDL level was increased in hypertension and diabetics as compared with non-smokers. So there is a marked change in PON, SGOT, HDL and LDL values as compared to the normal.

\section{CONCLUSION}

From the present study, it was concluded the values of PON and HDL cholesterol were decreased. In the cardiac patients and as values of SGOT and LDL cholesterol were increased in the same patients..

\section{REFERENCES}

1. Frei, B. Cardiovascular disease and nutrient antioxidants: role of low-density lipoportein oxidation. Crit. Rev. Food Sci. Nutr., 1995; 35(12):83-98

2. Aviram, M. Interaction of oxidized low density lipoprotein with macrophages in atherosclerosis, and the antiatherogenicity of anti-oxidants. Eur. J Clin. Chem. Clin. Biochem. 1996; 34(8):599-608.

3. Xie, X.M. and S.P. Zhao. Congestive heart failure and paraoxonase. Human Yi Ke Da Xue Xue Bao. $2002 ; 27(2): 157-158$.

4. Bonafe, M., F. Marchegiani, M. Cardelli, F et al. Genetic analysis of paraoxonase (PON1) locus reveals an increased frequency of Arg 192 allele in centenarians. Euro. J. human Genetics. 2002; 10(5):292-296.

5. Jialal, J. and Fuller C.J. Effect of vitamin E, Vitamin $C$ and beta-carotene on LDL oxidation and atherosclerosis. Can. J. Cardiol. 11(Suppl. G): 1995; $97 \mathrm{G}-103 \mathrm{G}$

6. Jarvik, G.P, Tsai N.T, Mckinstry L.A. Mckinstry et al Vitamin $C$ and $E$ intake is associated with increased paraoxonase activity source. Arteriosclerosis thrombosis and vascular biology. 2002, 22(8):1329-1333.

7. James, R.W., Leviev I. and R. Righetti. Smoking is associated with reduced serum paraoxonase activity and concentration in patients with coronary artery disease. Circulation. 2000; 101(19):2252-2257.

8. Boemi, M.I., Leviev, C. Sirolla, C. Pieri, M. Marra and $W$. James. Serum paraoxonase is reduced in type-I diabetic patients compared to non-diabetic, first degree relatives; influence on the ability of HDL to protect LDL from oxidation. Atherosclerosis. 2001; 155(1):229-235.

9. Edwards, C.R.W. and Bouchier I.A.D.. Davidson's Principles and Practice ofMmedicine. $16^{\text {th }} \mathrm{Ed}$. Oxford University Press 1991.

10. Sheikh, M.A. A study of protein glycation (non enzymatic glycosylation). Ph.D. Thesis, Dept. of Bio. Sci. Biotech. Univ. of Strathcylde, Glasgow, UK. 1991.

11. Richardson. J, Woodak A.D, Atkinson L, Saunders J.B and Jewitt E. Relation between alcohol intake, myocardial enzyme activity and myocardial function in dilated cardiomyopathy. Br Heart J. 1986; 56:165-170.

12. Watson, A.D., Berliner JA, Hama SY,Fall LA D.U B.N. K.F, Fogelman AM. Protective effect of high density lipoprotein associated paraxonase. Inhibition of biological activity of minimally oxidized low density lipoprotein. J. Clin Invert. $1995 ; 96: 2882-91$

13. Aviram, $M$, Rosenblat $M$, Bisgaier $C L$, Newton RS, Primo-Parmo SL and La-Du BN. Paraoxonase inhabits high-density lipoprotein oxidation and preserve its function. A possible peroxidative role for paraoxonase. J. Clin. Invest. 1998; 101(8):1581. 1590.

14. Mertens, A, Holvoet P. Oxidized LDL and HDL: antagonists in atherothrombosis. FASEB Journal. 2001; 15(2):2073-2084

15. Gan, K.N, Sonolen A, Eckerson HW, La-Dua Bn. Purification of human serum paraoxonase /crylesterase. Evidence for one esterase catalyze both activities. Metab Dispos. 1991; 19:100-6.

16. Steel, R.G.D. and Torrie JH. Principles and Procedures of Statistics. 2nd ed. McGraw Hill Book Co., Inc., New York, USA. 1984. 